\title{
Mampukah Kecerdasan Spiritual Memoderasi Hubungan Faktor Demografi Terhadap Manajemen Keuangan Pribadi Mahasiswa?
}

\author{
Nurul Humairo ${ }^{1}$, Indah Yuliana ${ }^{2}$ \\ 1,2 Manajemen Program, UIN Maulana Malik Ibrahim Malang, Indonesia \\ 1nurulhumairo194@gmail.com, 2 indahoty@manajemen.uin-malang.ac.id
}

\begin{abstract}
This study examines the effect of demographic factors on personal financial management with spiritual intelligence as a moderating variable. The sampling technique is proportionate random sampling, the number of research samples 388 students of State Islamic University Maulana Malik Ibrahim Malang. The test results indicate an influence on personal financial management. The positive influence of demographic factors with age characteristics on personal financial management. As for the characteristics of the sex found no influence on personal financial management. Spiritual intelligence as a moderating variable is able to strengthen the relationship between demographic factors and personal financial management of State Islamic University Maulana Malik Ibrahim Malang students. The implications of this study can be used by education providers to ial design financeducation patterns for students.

Keywords: Demographic factors, Personal financial management, Spiritual
\end{abstract} intelligence.

History of Article:

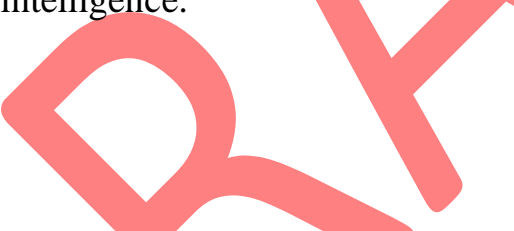

Citation:

Humairo, N \& Yuliana, I (2020) Mampukah Kecerdasan Spiritual Memoderasi Hubungan Faktor Demografi terhadap Manajemen Keuangan Pribadi Mahasiswa? Jurnal Pendidikan Ekonomi, 13(1), 08-17

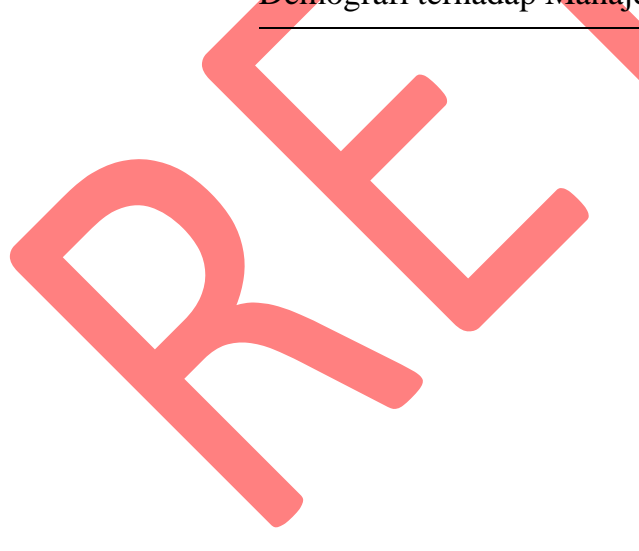

(C) Universitas Negeri Malang 


\section{PENDAHULUAN}

Manajemen keuangan pribadi merupakan suatu kegiatan merencanakan, mengatur, dan mengawasi finansial atau keuangan pribadi. Pentingnya mengelola keuangan pribadi tidak disadari semua pihak. Pengetahuan tentang keuangan sangat penting dalam pengelolaan keuangan individu. Sering sekali melihat fenomena masyarakat luas yang mengalami kesulitan dalam mengelola uangnya, bukan diakibatkan jumlah pendapatan yang sedikit, akan tetapi kurangnya pengetahuan dalam pengelolaan keuangan pribadi. Adanya pengetahuan dalam mengelola keuangan tersebut, individu akan mampu mengelola keuangannya, sehingga akan memperoleh keuntungan yang semakin besar dan dapat meningkatkan taraf kehidupannya, memiliki sikap perilaku keuangan yang baik juga penting untuk seorang individu agar masalah keuangan tidak menghampirinya (Safitri \& Sukirman, 2018). Banyak manfaat yang bisa didapat apabila dapat mengelola keuangan dengan baik, antara lain melatih pola hidup hemat, melatih untuk lebih tertib dan teratur, memiliki perlindungan dari perencanaan yang tidak terduga, menghindari diri dari utang, dan masa depan yang terencana dengan baik. Manajemen keuangan dikatakan baik apabila mampu mengelola uang yang masuk dan keluar, memanajemen hutang, memiliki tabungan dan melakukan investasi (Laily, 2016).

Berdasarkan hasil empiris, seseorang dalam mengelola keuangannya dipengaruhi beberapa faktor, diantaranya adalah faktor demografi. Karakteristik dari demografi yaitu umur, gender, status kawin, pendapatan, dan tingkat pendidikan (Lai \& Tan, 2009; Purwidianti \& Mudjiyanti, 2016). Usia muda sering mengalami kesulitan dalam mengontrol keluar masuknya uang mereka karena faktor ekonomi, seperti tabungan rendah dan pendapatan tidak teratur, mengakibatkan mereka menghadapi kekurangan dana yang berdampak pada bagaimana mereka mempertahankan gaya hidup (Bamforth, Jebarajakirthy, \& Geursen, 2018). Kelompok usia dewasa akan lebih bijakasana dalam mengatur pengeluaran keuangannya dibandingkan dengan usia muda (Hidayat \& Sinaga, 2017). Akan tetapi, kemampuan usia muda dalam mengelola keuangan akan berkembang seiring berjalannya waktu. Hal ini disebabkan karena situasi keuangan yang berubah selama bertahun-tahun, dan diikuti dengan respons individu terhadap pengelolaan situasi tersebut (Serido, Shim, \& Tang, 2013). Berbeda dengan hasil penelitian Vhalery, Leksono, \& Irvan (2018), yang tidak menemukan adanya pengaruh usia terhadap pengelolaan keuangan mahasiswa.

Disisi lain, karakteristik demografi yang diduga berpengaruh adalah jenis kelamin. Berdasarkan hasil empiris ada perbedaan antara laki-laki dengan perempuan dalam mengelola keuangan. Adanya dorongan lebih tinggi yang dimiliki perempuan dalam melakukan pembelian dibandingkan dengan laki-laki (Sapitri \& Suprapti, 2014). Akan tetapi, pada perempuan yang telah berkeluarga cenderung melihat kembali apa yang telah mereka lakukan terhadap uang yang mereka miliki dibanding laki-laki (Sina, 2013). Apabila dilihat dari keputusan untuk berinvestasi, perempuan lebih menentang resiko daripada lakilaki (Stendardi, Graham, \& O'Reilly, 2006). Hal ini disebabkan karena laki-laki lebih percaya diri tentang pengetahuan mereka mengenai pasar saham (Baker, Kumar, Goyal, \& Gaur, 2019; Mishra \& Metilda, 2015). Menurut Ansong \& Gyensare (2012), laki-laki memiliki tingkat pengetahuan keuangan lebih tinggi daripada perempuan. Akan tetapi, pernyataan diatas bertolak belakang dengan hasil penelitian Hidayat \& Sinaga (2017) tidak menemukan adanya pengelolaan keuangan yang berbeda antara laki-laki dengan perempuan.

Penelitian ini dilakukan untuk menganalisis perilaku mahasiswa S1 UIN Maliki Malang dalam pengelolaan keuangan pribadi. Terdapat 12867 mahasiswa aktif angkatan 2016 sampai 2019. Tujuan penelitian ini untuk menguji hubungan antara faktor demografi 
dengan manajemen keuangan pribadi dan bagaimana variabel kecerdasan spiritual memoderasi hubungan antara faktor demografi terhadap manajemen keuangan pribadi. Karakteristik demografi yang digunakan adalah usia dan jenis kelamin. Dilihat dari sisi kecerdasan spiritual, Mahasiswa UIN Maliki Malang ditanamkan sifat spiritual sejak semester 1, adanya aturan bahwa seluruh mahasiswa tahun pertama harus tinggal di pesantren kampus yang letaknya di lingkungan kampus. Saat tinggal di sana mahasiswa diajarkan Taklim al-Qur'an, Taklim Afkar, Bahasa Arab serta Bahasa Inggris. Tidak hanya itu, ekonomi dan sosial juga dikaji dalam sisi keislaman. Pembelajaran tersebut diharapkan agar mahasiswa UIN Maliki Malang tidak hanya belajar mengkaji ilmu-ilmu umum, tetapi juga mengkaji ilmu keislaman.

Disamping itu, peneliti juga ingin menguji apakah kecerdasan spiritual sebagai mampu memperkuat atau justru memperlemah pengaruh faktor demografi terhadap manajemen keuangan pribadi, hasil empiris mengatakan bahwa tidak ada pengaruh signifikan kecerdasan spiritual terhadap manajemen keuangan pribadi (Faridawati \& Silvy, 2019; Sina \& Noya, 2012). Hasil penelitian ini diperkuat oleh (Ayranci, 2011), faktor kecerdasan spiritual berpengaruh sangat lemah terhadap manajemen keuangan pribadi. Akan tetapi, pernyataan diatas bertolak belakang dengan penelitian (Chotimah \& Rohayati, 2015), bahwa manajemen keuangan pribadi tidak dipengaruhi oleh kecerdasan spiritual. Hasil penelitian terdahulu yang yang berbeda membuat peneliti mengambil celah penelitian tentang pengaruh faktor demografi yang dimoderasi oleh kecerdasan spiritual terhadap manajemen keuangan pribadi, dan tujuan penelitian ini adalah untuk mengetahui pengaruh faktor demografi terhadap manajemen keuangan pribadi yang dimoderasi oleh kecerdasan spiritual.

\section{METODE PENELITIAN}

Penelitian ini adalah penelitian deskriptif kuantitatif. Populasi dalam penelitian ini yaitu Mahasiswa S1 UIN Maliki Malang angkatan 2016 sampai 2019 yang berjumlah 12867 mahasiswa. Menggunakan teknik pengambilan sampel secara acak dengan memperhatikan proporsi dalam populasi tersebut yang disebut teknik proportionate random sampling. Jumlah sampel dari populasi ditentukan dengan rumus Slovin

$\mathrm{n}=\frac{N}{N e^{2}+1}$

Keterangan:

$\mathrm{n}=$ jumlah sampel

$\mathrm{N}=$ ukuran populasi

$\mathrm{e}=$ error margin.

Dengan menggunakan error margin sebesar 5\% didapatkan jumlah sampel sebanyak 388 mahasiswa, dengan rincian sebagai berikut.

Tabel 1. Jumlah sampel yang digunakan

\begin{tabular}{lcccc} 
Mahasiswa Angkatan & $\mathbf{2 0 1 6}$ & $\mathbf{2 0 1 7}$ & $\mathbf{2 0 1 8}$ & $\mathbf{2 0 1 9}$ \\
\hline Ekonomi & 12 & 12 & 16 & 16 \\
Humaniora & 12 & 12 & 12 & 12 \\
Saintek & 19 & 16 & 19 & 23 \\
\hline Ilmu Tarbiyah dan Keguruan & 23 & 23 & 23 & 27 \\
\hline Syariah & 16 & 16 & 16 & 19 \\
\hline Psikologi & 8 & 8 & 8 & 8 \\
\hline Kedokteran dan Ilmu Kesehatan & 4 & 4 & 4 & 4 \\
\hline
\end{tabular}

Sumber: data diolah (2019) 
Ada 2 data dalam penelitian ini, data primer yang diperoleh dari hasil survey penyebaran kuesioner online dan offline yang diberikan kepada Mahasiswa S1 UIN Maliki Malang, dan data sekunder diperoleh dari BAK Pusat untuk mengetahui jumlah seluruh Mahasiswa S1 UIN Maliki Malang yang masih aktif. Penelitian ini menggunakan 3 variabel, yaitu variabel independent, variabel dependent, dan variabel moderasi. Variabel independent penelitian ini adalah faktor demografi dengan karakteristik yang digunakan adalah usia dan jenis kelamin (Hidayat \& Sinaga, 2017).

Variabel dependent yang digunakan yaitu manajemen keuangan pribadi dengan 3 indikator yang digunakan, yaitu perilaku perencanaan keuangan, perilaku pengendalian pengeluaran, dan perilaku pengawasan keuangan (Sapitri \& Suprapti, 2014). Kecerdasan spiritual sebagai variabel moderasi dengan 4 indikator yang digunakan untuk mengukur, yaitu menerima setiap kritik dan saran dengan ikhlas, memiliki prinsip dalam hidup, selalu melakukan intropeksi diri, dan memiliki sikap kontrol diri (Sina \& Noya, 2012). Analisis data penelitian ini menggunkana Statistik deskriptif dan Moderated Regression Analysis (MRA). Kerangka konspetual penelitian adalah sebagai berikut.

Gambar 1. Kerangka Konseptual Penelitian

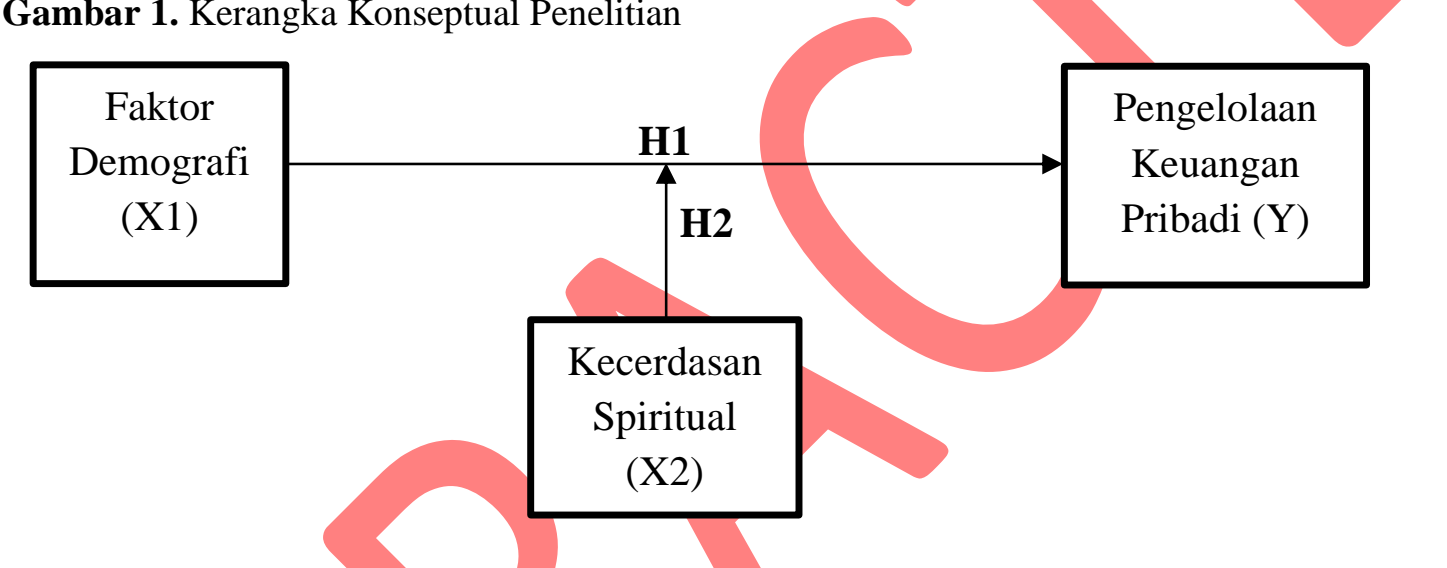

\section{HASIL DAN PEMBAHASAN}

Sebanyak 388 kuesioner yang terkumpul dan dapat digunakan analisis data lebih lanjut. Dari kuesioner tersebut diperoleh komposisi data sebagai berikut:

Tabel 2. Komposisi Usia dan Jenis Kelamin

\begin{tabular}{|cccc}
\hline Indikator & Kelompok & Frekuensi & Prosentase (\%) \\
\hline Usia & $17-18$ tahun & 91 & 23,5 \\
\hline & $19-21$ tahun & 174 & 44,8 \\
\hline & $22-24$ tahun & 123 & 31,7 \\
\hline Jenis Kelamin & Laki-laki & 142 & 36,6 \\
\hline & Perempuan & 246 & 63,4 \\
\hline
\end{tabular}

Sumber: data diolah (2019)

Hasil Tabel 2 menunjukkan bahwa dari 388 responden yang telah mengisi kuesioner. Jumlah responden yang berusia 17-18 tahun terdiri dari 91 responden dengan prosentase 23,5\%, 123 responden dengan usia 22-24 tahun. Usia 19-21 tahun mendominasi kategori usia dengan jumlah sebanyak 174 responden. Pada kategori jenis kelamin, didominasi oleh responden perempuan dengan prosentase $63,4 \%$ yaitu sebanyak 246 responden, sedangkan responden laki-laki berjumlah 142 responden. 
Tabel 3. Statistik Deskriptif

\begin{tabular}{cccccc}
\hline Variabel & Jumlah & $\begin{array}{c}\text { Nilai } \\
\text { terendah }\end{array}$ & $\begin{array}{c}\text { Nilai } \\
\text { tertinggi }\end{array}$ & $\begin{array}{c}\text { Rata- } \\
\text { rata }\end{array}$ & $\begin{array}{c}\text { Standar } \\
\text { Deviasi }\end{array}$ \\
\hline FD & 388 & 2 & 5 & 3,72 & 0,913 \\
\hline PKP & 388 & 20 & 50 & 39,27 & 4,634 \\
\hline KS & 388 & 8 & 30 & 24,15 & 3,401
\end{tabular}

Sumber: data diolah (2019)

Tabel 3 menunjukkan bahwa sampel yang digunakan di penelitian ini adalah 388 responden. Nilai minimum variabel independen yaitu faktor demografi adalah 2 , maksimum 5, dan nilai rata-rata 3,72. Variabel dependen yaitu pengelolaan keuangan pribadi memiliki nilai minimum 20 , nilai maksimum 50 , dan nilai rata-rata 4,634. Sedangkan kecerdasan spiritual sebagai variabel moderasi dengan nilai minimum 8 , nilai maksimum 30 , dan nilai rata-rata sebesar 3,401.

Tabel 4. Hasil Uji Validitas dan Realibilitas

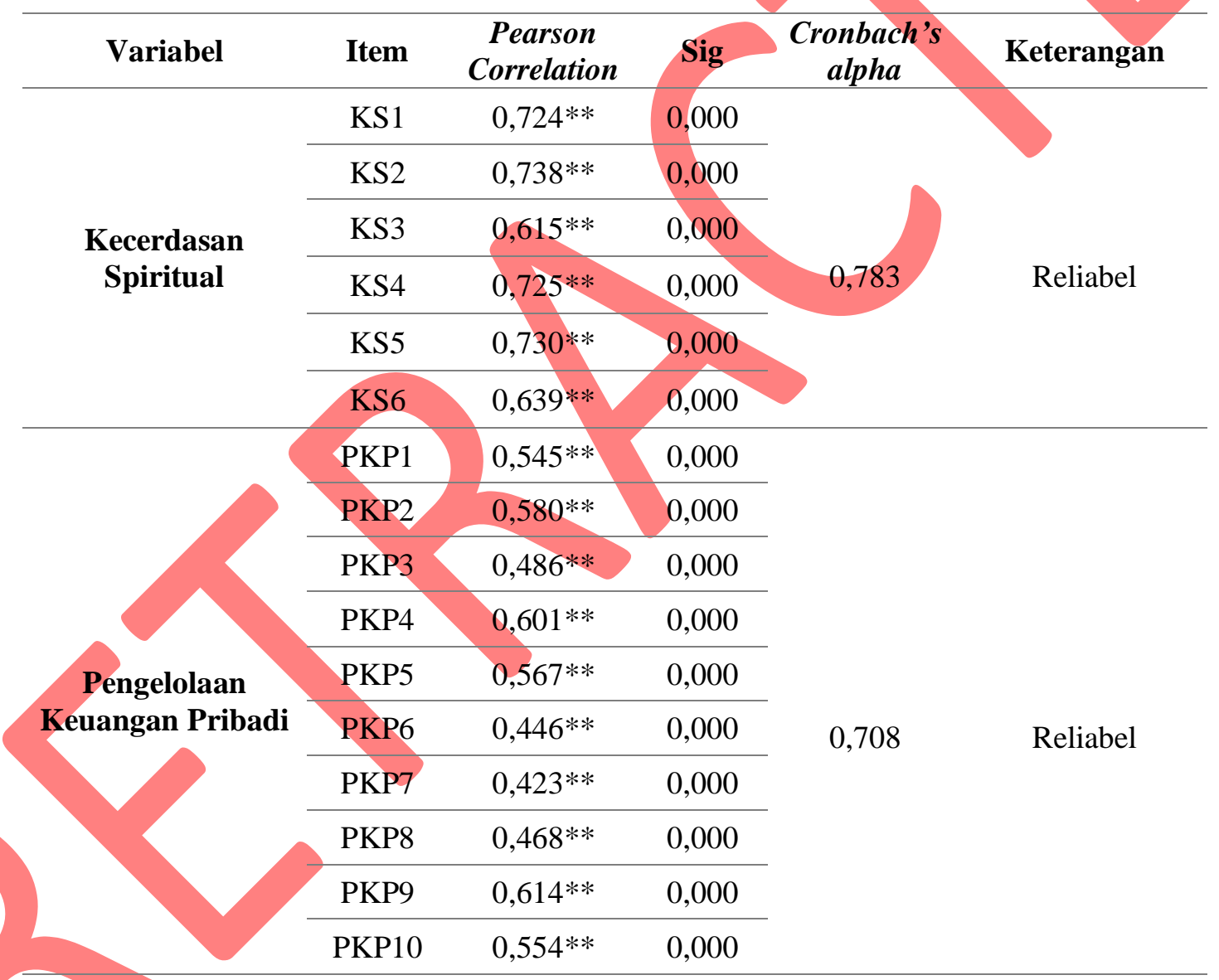

**. Correlation is significant at the level 0,01 level (2-tailed)

Sumber: data diolah (2019)

Berdasakan tabel 4 menunjukkan bahwa cronbach's alpha coefficient $>0,7$, dan syarat yang digunakan dalam melakukan uji reliabilitas adalah 0,7 , sehingga variabel diatas dinyatakan reliable dan nilai signifikansi hasil korelasi < 0,05 (5\%), sehingga item dinyatakan valid karena telah memenuhi syarat. Dan dapat dilakukan pengujian hipotesis. 
Tabel 5. Hasil Uji Regresi

\begin{tabular}{ccccc} 
& F hitung & t hitung & Sig & Kesimpulan \\
\hline FD $->$ PKP & 47,341 & - & 0,000 & Hipotesis Diterima \\
\hline Usia $->$ PKP & - & 9,708 & 0,000 & Hipotesis Diterima \\
\hline JK $->$ PKP & - & 1,410 & 0,159 & Hipotesis Ditolak \\
\hline
\end{tabular}

Sumber: data diolah (2019)

Berdasarkan hasil uji regresi pada tabel 5 diperoleh bahwa faktor demografi berpengaruh positif dan signifikan terhadap pengelolaan keuangan pribadi dengan $\mathrm{F}$ tabel $3,84<$ F hitung; signifikansi < 0,05. Adanya pengaruh secara positif dan signifikan faktor demografi dengan karakteristik usia terhadap manajemen keuangan pribadi ( tabel 1,960 < t hitung; signifikansi $<0,05)$ sedangkan tidak ditemukan adanya pengaruh jenis kelamin terhadap manajemen keuangan pribadi ( $\mathrm{t}$ hitung $<\mathrm{t}$ tabel 1,960; sig $>0,159$ ).

Tabel 6. Hasil Uji Moderated Regression Analysis Faktor Demografi terhadap Pengelolaan Keuangan Pribadi di Moderasi Kecerdasan Spiritual

\begin{tabular}{lcccccc}
\hline \multicolumn{1}{c}{$\begin{array}{c}\text { Variabel bebas dan } \\
\text { Moderasi }\end{array}$} & \multicolumn{2}{c}{ Tahap I } & \multicolumn{2}{c}{ Tahap II } & \multicolumn{2}{c}{ Tahap III } \\
\cline { 2 - 7 } & Beta & Sig & Beta & Sig & Beta & Sig \\
\hline Faktor Demografi $(\mathbf{X 1})$ & 0,340 & 0,000 & 0,185 & 0,000 & $-0,562$ & 0,002 \\
\hline Kecerdasan Spiritual $(\mathbf{Z})$ & & & 0,552 & 0,000 & 0,184 & 0,60 \\
\hline $\mathbf{X 1} * \mathbf{Z}$ & & & & & 0,934 & 0,000 \\
\hline $\boldsymbol{R}$ Square & 0,115 & & 0,396 & & 0,422 & \\
\hline
\end{tabular}

Sumber: data diolah (2019)

Pada tabel 6, tahap 1 menunjukkan bahwa adanya pengaruh positif dan signifikan faktor demografi terhadap manajemen keuangan pribadi dengan nilai signifikansi $0,000<$ 0,05 . Di tahap 2 diperoleh bahwa ada pengaruh secara positif kecerdasan spiritual terhadap manajemen keuangan pribadi dan nilai sig $0,000<0,05$. Pada tahap terakhir variabel $\mathrm{X} 1 * \mathrm{Z}$ berpengaruh terhadap manajemen keuangan pribadi dengan nilai signifikansi $0,000<0,05$. Hal ini menunjukkan bahwa variabel kecerdasan spiritual mampu memoderasi faktor demografi terhadap pengelolaan keuangan pribadi. Selain itu, nilai $R$ square juga meningkat dari 0,396 menjadi 0,422, dapat dikatakan bahwa kecerdasan spiritual adalah variabel moderasi yang memperkuat, sehingga kecerdasan spiritual merupakan quasi moderator yang memperkuat faktor demogarfi terhadap pengelolaan keuangan pribadi.

Tabel 7. Hasil Uji Moderated Regression Analysis Usia terhadap Pengelolaan Keuangan Pribadi di Moderasi Kecerdasan Spiritual

\begin{tabular}{|c|c|c|c|c|c|c|}
\hline \multirow{2}{*}{$\begin{array}{l}\text { Variabel indikator bebas } \\
\text { dan Moderasi }\end{array}$} & \multicolumn{2}{|c|}{ Tahap I } & \multicolumn{2}{|c|}{ Tahap II } & \multicolumn{2}{|c|}{ Tahap III } \\
\hline & Beta & Sig & Beta & Sig & Beta & Sig \\
\hline Usia (X1.1) & 0,440 & 0,000 & 0,271 & 0,000 & $-0,898$ & 0,000 \\
\hline Kecerdasan Spiritual (Z) & & & 0,515 & 0,000 & 0,100 & 0,279 \\
\hline $\mathrm{X} 1.1 * \mathrm{Z}$ & & & & & 1,374 & 0,000 \\
\hline R Square & 0,193 & & 0,429 & & 0,464 & \\
\hline
\end{tabular}

Sumber: data diolah (2019) 
Tabel 8. Hasil Uji Moderated Regression Analysis Jenis Kelamin terhadap Pengelolaan Keuangan Pribadi di Moderasi Kecerdasan Spiritual

\begin{tabular}{lcccccc}
\hline $\begin{array}{l}\text { Variabel } \\
\text { indikator bebas } \\
\text { dan Moderasi }\end{array}$ & \multicolumn{2}{c}{ Tahap I } & \multicolumn{2}{c}{ Tahap II } & \multicolumn{2}{c}{ Tahap III } \\
\cline { 2 - 7 } & Beta & Sig & Beta & Sig & Beta & Sig \\
\hline $\begin{array}{l}\text { Jenis Kelamin } \\
\text { (X1.2) }\end{array}$ & 0,030 & 0,598 & 0,048 & 0,240 & 0,323 & 0,040 \\
\hline $\begin{array}{l}\text { Kecerdasan } \\
\text { Spiritual (Z) }\end{array}$ & & 0,605 & 0,000 & 0,491 & 0,000 \\
\hline $\mathbf{X 1 . 2} * \mathbf{Z}$ & & & & & 0,310 & 0,070 \\
\hline R Square & 0,001 & & 0,366 & & 0,372 & \\
\hline Sumber: data diolah (2019) & & & & & \\
\hline
\end{tabular}

Berdasarkan tabel 7 dan 8, pada tahap 1 menunjukkan bahwa faktor demografi yang diukur dengan usia berpengaruh positif terhadap manajemen keuangan pribadi dengan signifikansi $0,000<0,05$, sedangkan tidak ditemukan pengaruh jenis kelamin terhadap manajemen keuangan pribadi karena nilai signifikansi 0,598 $>0,05$. Di tahap 2, tabel 7 dan 8 diperoleh ada pengaruh positif kecerdasan spiritual manajemen keuangan pribadi dan nilai signifikansi $0,000<0,05$. Pada tahap terakhir variabel $\mathrm{X} 1.1 * \mathrm{Z}$ berpengaruh terhadap manajemen keuangan pribadi dengan signifikansi $0,000<0,05$. Hal ini menunjukkan variabel kecerdasan spiritual mampu memoderasi karakteristik usia terhadap manajemen keuangan pribadi. Selain itu, nilai $R$ square juga meningkat dari 0,429 menjadi 0,464 , sehingga kecerdasan spiritual merupakan quasi moderator yang memperkuat faktor demografi yang diukur dengan usia terhadap manajemen keuangan pribadi. Pada tabel 8 tahap 3, karakteristik jenis kelamin berpengaruh positif terhadap manajemen keuangan pribadi dengan nilai signifikansi $0,04<0,05$ yang dimoderasi oleh kecerdasan spiritual dengan nilai beta 0,310 . Hal ini menunjukkan bahwa kecerdasan spiritual memperkuat hubungan karakteristik jenis kelamin terhadap manajemen keuangan pribadi yang dibuktikan dengan nilai $\mathrm{R}$ square yang meningkat dari 0,366 menjadi 0,372 dan nilai tidak signifikan 0,07>0,05. Dapat diartikan bahwa kecerdasan spiritual merupakan pure moderator yang memperkuat pengaruh faktor demogarfi yang diukur dengan jenis kelamin terhadap manajemen keuangan pribadi.

\section{Hubungan Faktor Demografi dengan Manajemen Keuangan Pribadi}

Hipotesis pertama yaitu ada pengaruh antara faktor demografi terhadap pengelolaan keuangan pribadi. Hasil analisis menunjukkan bahwa hipotesis pertama diterima. Ada 2 karakteristik faktor demografi yang digunakan dalam penelitian ini yaitu usia dan jenis kelamin. Penelitian ini juga menguji setiap karakteristik dan ditemukan hasil analisis sebagai berikut.

H1a. Ada pengaruh secara positif karakteristik usia terhadap manajemen keuangan pribadi

Hipotesis pertama poin a menyatakan bahwa faktor demografi yang diukur dengan usia berpengaruh positif terhadap pengelolaan keuangan pribadi. Hipotesis pertama poin a diterima, hasil analisis menemukan adanya pengaruh positif terhadap pengelolaan keuangan pribadi. Dapat diartikan semakin dewasa usia individu akan semakin bijak dalam pengelolaan keuangan pribadi. Usia dewasa memiliki pengalaman hidup yang lebih jika dibandingkan dengan usia remaja, dan usia dewasa telah mengalami pahit manis kehidupan sehingga membuat individu dengan usia yang lebih dewasa mampu mengelola keuangan pribadinya dengan penuh pertimbangan. Penelitian ini mendukung penelitian Hidayat \& 
Sinaga (2017) yang juga menemukan adanya pengaruh positif karakteristik usia terhadap pengelolaan keuangan pribadi, dan mendukung pernyataan Sapitri \& Suprapti (2014) dan Bamforth et al., (2018), bahwa usia remaja cenderung boros dalam pengeluaran dan juga sering mengalami kesulitan dalam mengontrol keluar masuknya uang mereka karena faktor ekonomi. Hasil penelitian ini berbeda dengan penelitian Vhalery et al., (2018), yang tidak menemukan adanya pengaruh usia terhadap manajemen keuangan.

\section{H1b. Ada perbedaan dalam mengelola keuangan antara laki-laki dan perempuan}

Hipotesis pertama poin $\mathrm{b}$ menyatakan bahwa faktor demografi yang diukur dengan jenis kelamin berpengaruh terhadap manajemen keuangan pribadi. Ada perbedaan antara perempuan dengan laki-laki dalam mengelola keuangan pribadi. Hasil analisis tidak menemukan adanya perbedaan antara laki-laki dan perempuan dalam mengelola keuangannya, sehingga hipotesis pertama poin b ditolak. Penelitian ini mendukung penelitian Hidayat \& Sinaga (2017), mengatakan tidak adanya pengaruh jenis kelamin terhadap manajemen keuangan pribadi. Dan diperkuat oleh Khairani (2019), yang tidak menemukan adanya perbedaan antara perempuan dengan laki-laki dalam mengelola keuangan. Akan tetapi, hasil penelitian ini bertolak belakang dengan pernyataan Dewi (2015) dan Sapitri \& Suprapti (2014), yang mengatakan bahwa wanita sering melakukan pengeluaran nakal atau pengeluaran yang tidak direncanakan dan juga memiliki dorongan yang lebih tinggi dalam pembelian dibandingkan dengan pria. Dan bertolak belakang dengan penelitian Andrew \& Linawati (2014), yang menemukan bahwa jenis kelamin berpengaruh signifikan terhadap pengelolaan keuangan.

\section{Kecerdasan spiritual memoderasi hubungan antara faktor demografi dengan manajemen keuangan pribadi}

Hipotesis kedua adalah kecerdasan spiritual mampu memoderasi pengaruh faktor demografi terhadap pengelolaan keuangan pribadi. Berdasarkan hasil analisis menunjukkan bahwa hipotesis kedua diterima. Kecerdasan spiritual sebagai variabel moderasi merupakan quasi moderator yang mampu memperkuat hubungan faktor demografi terhadap manajemen keuangan pribadi. Semakin tinggi tingkat spiritualitas seseorang maka akan semakin baik individu tersebut dalam mengelola keuangannya. Sejalan dengan teori Zohar \& Marshall (2007), yang mangatakan bahwa individu yang memiliki kecerdasan spiritual yang tinggi mampu membangun diri secara utuh dan meliki sikap kreatif dan berwawasan luas. Selain itu, Menurut Darmadi (2018) kecerdasan spiritual mampu memberikan makna dalam setiap perbuatan. Kecerdasan spiritual juga membuat invidu menjadi pribadi yang memiliki sikap tanggung jawab, mandiri, jujur dan optimal (Chotimah \& Rohayati, 2015), sehingga dia akan bersikap jujur kepada dirinya sendiri atas kesalahan-kesalahan yang dia lakukan dalam mengelola keuangannya, sehingga individu tersebut akan melakukan instropeksi diri agar terbebas dari masalah keuangannya (Sina \& Noya, 2012).

Pada penelitian terdahulu juga ditemukan bahwa manajemen keuangan pribadi dipengaruhi oleh kecerdasan spiritual (Faridawati \& Silvy, 2019; Sina \& Noya, 2012). Akan tetapi, pernyataan diatas bertolak belakang dengan penelitian (Chotimah \& Rohayati, 2015), yang tidak menemukan adanya pengaruh kecerdasan spiritual terhadap manajemen keuangan pribadi. Hasil analisis juga menguji bagaimana peran kecerdasan spiritual sebagai variabel moderasi pada setiap karakteristik faktor demografi yang digunakan pada penelitian ini. Hasilnya menunjukkan bahwa: a) Pada karakteristik usia, kecerdasan spiritual mampu memperkuat hubungan antara karakteristik usia terhadap pengelolaan keuangan pribadi. Kecerdasan spiritual sebagai quasi moderator memperkuat hubungan usia ke pengelolaan 
keuangan pribadi dengan kenaikan koefisien determinasi lebih tinggi dibandingkan dengan karakteristik jenis kelamin; b) Pada karakteristik jenis kelamin, kecerdasan spiritual juga mampu memperkuat hubungan karakteristik jenis kelamin terhadap pengelolaan keuangan pribadi. Kecerdasan spiritual sebagai pure moderator yang memperkuat hubungan jenis kelamin ke pengelolaan keuangan pribadi, dengan koefisien determinasi yang lebih rendah.

\section{KESIMPULAN}

Berdasarkan hasil penelitian ini ditemukan adanya pengaruh positif faktor demografi terhadap manajemen keuangan pribadi pada Mahasiswa S1 UIN Maliki Malang. Faktor demografi yang diukur dengan karakteristik usia berpengaruh positif terhadap manajemen keuangan pribadi, yang artinya semakin dewasa usia individu maka akan semakin baik pula dalam mengelola keuangannya. Sedangkan, jenis kelamin tidak berpengaruh terhadap manajemen keuangan pribadi, tidak adanya perbedaan antara mahasiswa laki-laki dan perempuan UIN Maulana Malik Ibrahim Malang dalam mengelola keuangan pribadinya. Selanjutnya, kecerdasan spiritual sebagai variabel moderasi mampu memperkuat hubungan antara faktor demografi terhadap manajemen keuangan pribadi, semakin tinggi tingkat kecerdasan spiritual individu makan akan semakin bijak dalam mengelola keuangannya. Berdasarkan karakteristik, kecerdasan spiritual juga mampu memperkuat hubungan antara karakteristik jenis kelamin dan usia terhadap manajemen keuangan pribadi, ditemukan bahwa peningkatan koefisien determinasi usia lebih tinggi dibandingkan jenis kelamin, sehingga pengaruh usia yang dimoderasi kecerdasan spiritual lebih tinggi dibanding pengaruh jenis kelamin yang dimoderasi kecerdasan spiritual.

\section{REFERENSI}

Andrew, V., \& Linawati, N. (2014). Hubungan Faktor Demografi dan Pengetahuan Keuangan Dengan Perilaku Keuangan Karyawan Swasta di Surabaya. Finesta. Vol. 2(2): 35-39.

Ansong, A., \& Gyensare, M. A. (2012). Determinants of University Working-Students' Financial Literacy at the University of Cape Coast, Ghana. International Journal of Business and Management. Vol. 7(9): 126. doi: https://doi.org/10.5539/ijbm.v7n9p126.

Ayranci, E. (2011). Effect Of Top Turkish Managers' Emotional and Spiritual Intelligences on Their Organizations' Financial Performance. Financial Performance. Vol. 28.

Baker, H. K., Kumar, S., Goyal, N., \& Gaur, V. (2019). How financial literacy and demographic variables relate to behavioral biases. Managerial Finance. Vol. 45(1): 124-146. doi: https://doi.org/10.1108/MF-01-2018-0003.

Bamforth, J., Jebarajakirthy, C., \& Geursen, G. (2018). Understanding undergraduates' money management behaviour: A study beyond financial literacy. International Journal of Bank Marketing. Vol. 36(7): 1285-1310. doi: https://doi.org/10.1108/IJBM-05-2017-0104.

Chotimah, C., \& Rohayati, S. (2015). Pengaruh Pendidikan Keuangan di Keluarga, Sosial Ekonomi Orang Tua, Pengetahuan Keuangan, Kecerdasan Spiritual, dan Teman Sebaya terhadap Manajamen Keuangan Pribadi Mahasiswa S1 Pendidikan Akuntansi Fakultas Ekonomi Universitas Negeri Surabaya. Vol. 10.

Darmadi, H. (2018). Kecerdasan Spiritual. Bogor: Guepedia.

Dewi, H. P. (2015). Cerdas Mengelola Keuangan Pribadi. Yogyakarta: Stiletto Book. 
Faridawati, R., \& Silvy, M. (2019). Pengaruh niat berperilaku dan kecerdasan spiritual terhadap pengelolaan keuangan keluarga. Journal of Business \& Banking. Vol. 7(1). doi: https://doi.org/10.14414/jbb.v7i1.1465.

Hidayat, R., \& Sinaga, I. W. (2017). Pengaruh Faktor Demografi dan Kecerdasan Emosional terhadap Manajemen Keuangan Pribadi Mahasiswa Politeknik Negeri Batam. Vol. 11.

Khairani. (2019). Perbedaan Pengelolaan Keuangan Nagari berdasarkan Jenis Kelamin dan Tingkat Pendidikan di Kabupaten Tanah Datar. https://doi.org/10.31227/osf.io/py4uq.

Lai, M.-M., \& Tan, W.-K. (2009). An Empirical Analysis of Personal Financial Planning in an Emerging Economy. Vol. (16): 13.

Laily, N. (2016). Pengaruh Literasi Keuangan terhadap Perilaku Mahasiswa dalam Mengelola Keuangan. Journal of Accounting and Business Education. Vol. 1(4). doi: https://doi.org/10.26675/jabe.v1i4.6042.

Mishra, K. C., \& Metilda, M. J. (2015). A study on the impact of investment experience, gender, and level of education on overconfidence and self-attribution bias. IIMB Management Review. Vol. 27(4): 228-239. doi: https://doi.org/10.1016/j.iimb.2015.09.001

Purwidianti, W., \& Mudjiyanti, R. (2016). Analisis Pengaruh Pengalaman Keuangan Dan Tingkat Pendapatan Terhadap Perilaku Keuangan Keluarga Di Kecamatan Purwokerto Timur. Benefit: Jurnal Manajemen Dan Bisnis. Vol. 1(2): 141-148. doi: 10.23917/benefit.v1i2.3257.

Safitri, N. A., \& Sukirman. (2018). Analisis faktor-faktor yang mempengaruhi financial behavior. 14.

Sapitri, N. L. G. A., \& Suprapti, N. W. S. (2014). Hubungan Variabel Demografi Dengan Perilaku Pembelian Impulsif Yang Dimoderasi Kepemilikan Kartu Kredit di Kota Denpasar. E-Jurnal Manajemen. Vol. 3(10). https://ojs.unud.ac.id/index.php/Manajemen/article/view/9439.

Serido, J., Shim, S., \& Tang, C. (2013). A developmental model of financial capability: A framework for promoting a successful transition to adulthood. International Journal of Behavioral Development. Vol. 37(4): 287-297. doi: https://doi.org/10.1177/0165025413479476

Sina, P. G. (2013). Financial Efficacy dan Financial Satisfaction: Ditinjau dari Perbedaan Gender. Jurnal Manajemen. Vol. 12.

Sina, P. G., \& Noya, A. (2012). Pengaruh Kecerdasan Spiritual terhadap Pengelolaan Keuangan Pribadi. Jurnal Manajemen. Vol. 18.

Stendardi, E. J., Graham, J. F., \& O'Reilly, M. (2006). The impact of gender on the personal financial planning process: Should financial advisors tailor their process to the gender of the client? Humanomics. Vol. 22(4): 223-238. doi: https://doi.org/10.1108/08288660610710746.

Vhalery, R., Leksono, A. W., \& Irvan, M. (2018). Pengaruh Literasi Keuangan, Usia, dan Bimbingan Orang Tua terhadap Pengelolaan Uang Saku Mahasiswa UNINDRA. Vol. 8.

Zohar, D., \& Marshall, I. (2007). SQ - Kecerdasan Spiritual. Bandung: Mizan Pustaka. 